\title{
Gerrit Fey
}

Banken zwischen Wettbewerb, Selbstkontrolle und staatlicher Regulierung: Eine ordnungsökonomische Analyse 


\section{Schriften}

\section{zu Ordnungsfragen der Wirtschaft}

Herausgegeben von

Prof. Dr. Gernot Gutmann, Köln

Dr. Hannelore Hamel, Marburg

Prof. Dr. Helmut Leipold, Marburg

Prof. Dr. Alfred Schüller, Marburg

Prof. Dr. H. Jörg Thieme, Düsseldorf

Unter Mitwirkung von

Prof. Dr. Dieter Cassel, Duisburg

Prof. Dr. Karl-Hans Hartwig, Münster

Prof. Dr. Hans-Günter Krüsselberg, Marburg

Prof. Dr. Ulrich Wagner, Pforzheim

Redaktion: Dr. Hannelore Hamel

Band 80: Banken zwischen Wettbewerb, Selbstkontrolle und staatlicher Regulierung

$\underset{2}{2}$ Lucius \& Lucius $\cdot$ Stuttgart $\cdot 2006$ 


\section{Banken zwischen Wettbewerb, Selbstkontrolle und staatlicher Regulierung}

Eine ordnungsökonomische Analyse

Von

Gerrit Fey

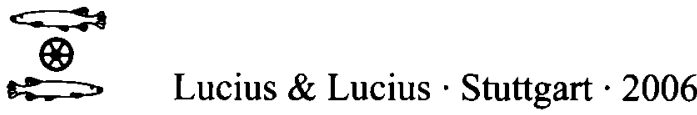


Anschrift des Autors:

Dr. Gerrit Fey

Ziegelhüttenweg 46

60598 Frankfurt am Main

e-mail: gerrit.fey@gmx.de

Bibliografische Information der Deutschen Bibliothek

Die Deutsche Bibliothek verzeichnet diese Publikation in der Deutschen Nationalbibliografie; detaillierte bibliografische Daten sind im Internet über http://dnb.ddb.de abrufbar.

(Schriften zu Ordnungsfragen der Wirtschaft; Bd. 80)

ISBN 3-8282-0364-7

(ab 2007: ISBN 978-3-0364-8)

Cucius \& Lucius Verlags-GmbH • Stuttgart • 2006

Gerokstraße 51 - D-70184 Stuttgart

www.luciusverlag.com

Das Werk einschließlich aller seiner Teile ist urheberrechtlich geschützt. Jede Verwertung außerhalb der engen Grenzen des Urheberrechtsgesetzes ist ohne Zustimmung des Verlages unzulässig und strafbar. Das gilt insbesondere für Vervielfältigungen, Übersetzungen, Mikroverfilmungen und die Einspeicherung, Verarbeitung und Übermittlung in elektronischen Systemen.

Druck und Einband: ROSCH-BUCH Druckerei GmbH, 96110 Scheßlitz Printed in Germany

\section{ISBN 3-8282-0364-7}

ISSN 1432-9220 